\title{
Skin Delivery of Glucosamine and Chondroitin Sulphates-A Perspective on the Conservative Treatment for Osteoarthritis of the Knee
}

\author{
Cláudia Batista Siqueira Leite¹, Janaína Moreira Coelho', Luis Alexandre Muehlmann², \\ Ricardo Bentes de Azevedo ${ }^{3}$, Marcelo Henrique Sousa ${ }^{2}$ \\ ${ }^{1}$ Institute of Biological Sciences, University of Brasília, Brasília, Brazil \\ ${ }^{2}$ Faculty of Ceilândia, University of Brasília, Brasília, Brazil \\ ${ }^{3}$ Department of Genetics and Morphology, Institute of Biological Sciences, University of Brasília, Brasília, Brazil \\ Email: claudiasiqueiraleite@yahoo.com.br, mhsqui@gmail.com
}

How to cite this paper: Leite, C.B.S., Coelho, J.M., Muehlmann, L.A., de Azevedo, R.B. and Sousa, M.H. (2017) Skin Delivery of Glucosamine and Chondroitin Sulphates-A Perspective on the Conservative Treatment for Osteoarthritis of the Knee. Journal of Biosciences and Medicines, 5, 11-20.

https://doi.org/10.4236/jbm.2017.54002

Received: December 14, 2016

Accepted: April 25, 2017

Published: April 30, 2017

Copyright $\odot 2017$ by authors and Scientific Research Publishing Inc. This work is licensed under the Creative Commons Attribution International License (CC BY 4.0).

http://creativecommons.org/licenses/by/4.0/

(c) $\underset{\mathrm{EY}}{\text { (i) Open Access }}$

\begin{abstract}
Based upon a series of research studies, scientific organizations considered Glucosamine and Chondroitin "not appropriate" as osteoarthritis (OA) of the knee modifying drugs and uncertain as pain relievers. Research studies which served as foundation for the aforementioned conclusions focused on the oral use of the substances. On the other hand, studies recommend that topical administration in treating OA be considered first line therapy, since it is said to be advantageous for its efficacy in treating localized situations, as it allows greater local concentration and it results in smaller systemic effects. Studies found did not provide sufficient evidence for good development and application strategies and were not enough to prove the technique to be effective or non-effective. Several other aspects must be clarified. In order to enhance permeation and delivery of Glucosamine and Chondroitin to knee joint, combining the advantages of intravenous infusion therapy with the convenience of oral administration, the suggested course of action is to transform skin delivery technology, while clarifying other points discussed throughout this research study.
\end{abstract}

\section{Keywords}

Osteoarthritis of the Knee, Glucosamine, Chondroitin, Skin Delivery, Nanotechnology

\section{Introduction}

There has been much debate about Osteoarthritis (OA) of the knee and its 
common incidence among men and women of all ages. Affected patients may experience pain first thing in the morning or complain about pain and muscle stiffness after staying in the same position for extended periods of time. Some swelling and a cracking sensation may be noticed and pain tends to worsen as physical effort increases throughout the day [1]. The use of medication to treat symptoms is often recommended by physicians. Many use alternative therapies and surgical intervention to address OA symptoms [2].

OA treatment guidelines developed by scientific organizations are often debated. The American College of Rheumatology (ACR), the Osteoarthritis Research Society International (OARSI), and the American Academy of Orthopedic Surgeons (AAOS) are among those organizations. Their guidelines are based upon high-quality evidence provided by systematic review studies, meta analyses, and randomized controlled trials [3].

In that regard, in 2012, the ACR updated both with and without drug treatment guidelines for OA of the hand, hip, and knee. The new guidelines were developed following the Grading of Recommendations Assessment Development and Evaluation-GRADE system, a formal and systematic approach to developing strong clinical recommendations based upon evidence. It is the result of the work performed by specialists from the US and Canada. The purpose of the bibliographic research was to identify systematic reviews and meta analyses which would provide reliable estimates for the benefits of a given intervention. It is important to highlight that among several ACR guidelines, there were recommendations against the use of Glucosamine and Chondroitin on patients affected by OA of the knee. Such recommendation is based on the lack of highquality evidence, or a small difference between desirable and undesirable effects during treatment [4]. In addition, AAOS guidelines, published in 2013, also contained a strong recommendation against the use of Glucosamine and Chondroitin for the same reasons as ACR's [5].

It is important to note that, in 2014, the OARSI brought together 13 physicians from relevant specialties (Primary Care, Rheumatology, Orthopedics, Physical Therapy, Physical and Rehabilitation Medicine, and Evidence-Based Medicine), from three continents and ten countries (United States, United Kingdom, France, Netherlands, Belgium, Sweden, Denmark, Australia, Japan, and Canada) and a patient representative. The purpose of this meeting was to provide guidelines and instructions for a non-surgical approach to OA of the knee. Based on OARSI's previous guidelines and a systematic literature review, 29 therapy modalities were recommended for OA treatment. According to OARSI's guidelines, both Glucosamine and Chondroitin were considered "not appropriate" as disease-modifying drugs and uncertain as pain relievers [6].

The research studies which served as foundation for the guidelines focused on the oral use of Glucosamine and Chondroitin. That can be easily explained as there are few research studies targeted at other Glucosamine and Chondroitin routes of administration. It was possible to note that the skin delivery of these 
substances, for instance, was not mentioned in any of the therapy recommendations for OA of the knee.

However, it is general knowledge that the topical route for drug holds advantage to other routes of administration-under several circumstances. Hepatic first-pass effect, very common for drugs administered orally, is responsible for decreased bioavailability and drug degradation. The topical route prevents the first-pass effect from occurring [7]. Furthermore, a number of undesirable side effects may be noticed when orally administering drugs, such as nausea, dyspepsia, diarrhea, constipation, ulcer, and mucosal bleeding-which does not occur when applying the topical route [8] [9]. It is important to add that the topical route holds advantage over both the intravenous and intramuscular routes as it is a painless and noninvasive route of administration, enhancing patients' adherence to recommended therapy [10] [11] [12].

It is reported that the European League Against Rheumatism (EULAR), the National Institute for Clinical Excellence (NICE), and the European Society for Clinical and Economic Aspects of Osteoporosis and Osteoarthritis (ESCEO) indicated that transdermal drugs may be used either combined with or as an alternative to oral drugs in OA treatment. They also recommended that the skin delivery be considered first line therapy for all patients [13].

It is important to report that chondrocytes synthesize the various types of proteoglycans and these allow the cartilaginous tissue the ability to withstand high compression forces. Proteoglycans are responsible for the morphological structure and nutrition of the cartilaginous cells. It is expected that by providing Glucosamine and Chondroitin-since they participate in the proteoglycans synthesis-there will be an improvement in the biological conditions of the tissue [14] [15]. Therefore, it is important that Skin delivery provides a transdermal permeation, that is, transposes GS and CS through the stratum corneum and the basal epidermis and to reach the dermis. Only then, will the technique be able to exert its therapeutic effect.

In light of the above, and considering there is the need for new treatment regimens for OA of the knee, the purpose of this research study was to examine available literature on treatments for OA of the knee with skin delivery of Glucosamine and Chondroitin while seeking to identify new approaches to this technique in treating the condition.

\section{Method}

Literature review with the use of Medline, Pubmed and Web Of Science databases. The keywords in this research were "glucosamine", "chondroitin", "osteoarthritis", "knee", skin, transdermal and "topical". Inclusion criteria: clinical trials comparing the topical use of Glucosamine and Chondroitin with placebo, other medication, or another administration route. Reviews discussing the topical use of those substances in humans were also included in this study. Exclusion criteria: Animal study, reviews that did not focus on topical administration of the drugs in question, and clinical trials with other routes of administration. 


\section{Results}

52 potentially relevant articles were identified by combining keywords. In the first phase of the analysis 9 duplicate articles were excluded. The full text of 43 articles was revised. 38 studies were excluded, with 22 reviews with little approach to topical use, 4 clinical investigations without direct interventions in humans, 3 clinical trials with other routes of administration and 9 short reports. 5 articles met the inclusion criteria (an overview and other comments are included in Table 1).

In the work performed by Cohen et al. [16], 63 patients suffering from OA of the knee were randomly divided into two groups. The first group received skin delivery of GS and CS and the second group received placebo. Pain was measured using a Visual Analog Scale (VAS) and physical function was measured using the Western Ontario and McMaster Universities Osteoarthritis Index (WOMAC). Results demonstrated significant pain relief for the group undergoing treatment. On the other hand, there was no significant WOMAC difference between the two treatment groups.

In a different study, Erhan et al. [17] used topical GS and CS associated with muscle strength exercises. Forty-nine patients with OA of the knee were randomized into two groups. It was a double-blind study. The first group, consisting of 27 patients, received physical therapy and topical GS. The second group consisted of 22 patients and received physical therapy and placebo. Results were analyzed using VAS, WOMAC, and radiological findings. As a final result, no significant difference was demonstrated between the two groups. Hammad et al. [18] randomly divided 180 patients with OA of the knee into two groups. GS and CS were orally administrated on the first group and the second group received skin delivery. Results were analyzed using radiographs, VAS, and

Table 1. Summary of articles included in the review.

\begin{tabular}{|c|c|c|c|}
\hline Ref. & Type of study & $\begin{array}{l}\text { Assessment } \\
\text { methods }\end{array}$ & Results and comments \\
\hline $\begin{array}{c}\text { Cohen } \\
\text { et al., [16]. }\end{array}$ & $\begin{array}{l}\text { Randomized } \\
\text { Placebo }\end{array}$ & ${ }^{*}$ VAS and ${ }^{* *}$ WOMAC & $\begin{array}{l}\text { VAS scores higher for group } \\
\text { undergoing treatment. There was no } \\
\text { WOMAC difference. }\end{array}$ \\
\hline $\begin{array}{c}\text { Erhan } \\
\text { et al., [17]. }\end{array}$ & $\begin{array}{l}\text { Randomized, Placebo, } \\
\text { Double blind }\end{array}$ & $\begin{array}{l}\text { VAS and WOMAC } \\
\text { Radiography }\end{array}$ & $\begin{array}{c}\text { No significant difference demonstrated } \\
\text { between the two groups. }\end{array}$ \\
\hline $\begin{array}{l}\text { Hammad } \\
\text { et al., [18]. }\end{array}$ & $\begin{array}{l}\text { Randomized } \\
\text { Oral route versus } \\
\text { topical route }\end{array}$ & $\begin{array}{l}\text { VAS and WOMAC } \\
\text { Radiografia }\end{array}$ & $\begin{array}{c}\text { Skin delivery superior in improving } \\
\text { joint stiffness. No significant } \\
\text { differences in other aspects. }\end{array}$ \\
\hline $\begin{array}{l}\text { Onigbinde } \\
\text { et al. [19]. }\end{array}$ & $\begin{array}{l}\text { Randomized } \\
3 \text { groups: } \\
\text { GS and exercise }\end{array}$ & VAS & $\begin{array}{c}\text { No significant difference } \\
\text { demonstrated between the two groups. }\end{array}$ \\
\hline $\begin{array}{l}\text { Onigbinde } \\
\text { et al. }[20] .\end{array}$ & $\begin{array}{c}\text { Randomized } \\
\text { GS versus NSAIDs }\end{array}$ & VAS & $\begin{array}{c}\text { No significant difference } \\
\text { demonstrated between the two groups. }\end{array}$ \\
\hline
\end{tabular}

*VAS (Visual Analogue Scale), ${ }^{*}$ WOMAC (Western Ontario and McMaster Universities Osteoarthritis Index). 
WOMAC. No significant differences were found between the two groups regarding pain relief and improvement in physical function. In that case, the result of skin delivery was superior in improving joint stiffness.

Onigbinde et al. [19] compared the efficacy of exercise therapy and GS iontophoresis. Fifty-two individuals with OA of the knee were randomly grouped into 3. Group 1 received exercise therapy and GS iontophoresis. Group 2 received GS iontophoresis only. Group 3 received exercise therapy only (cycle ergometry). The analysis of variance determined that there were no significant differences in pain levels of the 3 groups. All three techniques were effective in managing pain. Onigbinde et al. [20] analyzed the immediate effects on pain and knee flexibility on two groups of patients with OA of the knee. The first group received topical GS and the second group received topical methyl salicylate. Forty-one patients with grade II knee OA were recruited. One gram of each topical formulation was administered to the knee joint using massage. There was significant reduction in pain intensity and improvement in flexibility across the two groups. However, there were no significant differences between them. It is important to stress that in addition to bicycle ergometry sessions, both groups received infrared radiation.

\section{Discussion}

Analyzing studies specifically targeted to skin delivery of GS and CS, there was a variation between aqueous vehicles and creams. The daily amount varied from $215 \mathrm{mg}$ to $1000 \mathrm{mg}$ Glucosamine and from 170 to $780 \mathrm{mg}$ Chondroitin. The methodology used in the research studies was not very clear on whether the daily amount was for a single application or fractionated into multiple applications. There was no pattern followed as far as application techniques are concerned. There was variation between association of exercises with iontophoresis and infrared, together with skin delivery of substances.

Across the studies included, it was possible to note that different parameters were used in the formulation, concentration, dosage, and application technique, causing difficulty in the conclusion process. Skin delivery of Glucosamine and Chondroitin is not yet fully explored in literature.

Many original articles have assessed the effects of Glucosamine and Chondroitin. Most research studies focus on the oral use of those substances. They are frequently used with the purpose to treat OA pain. Wilson et al. [2] have performed a study of the prevalence of use and combinations of different medications for OA in 238,536 participants in Catalonia, Spain. The most common treatment regimen consisted of at least three drugs (53.9\% of patients). The drugs most frequently used were Chondroitin (21.2\%), Glucosamine (15.8\%), and NSAIDs (14.4\%).

Glucosamine and Chondroitin are natural compounds found in healthy cartilage. Articular cartilage is a highly specialized tissue composed of chondrocytes, collagen, proteoglycans, and water. Preserving the integrity of articular cartilage components is essential to guaranteeing proper function of articulations. Gluco- 
samine is a substrate used in the synthesis of glycosaminoglycans and proteoglycans found in cartilage matrix and synovial fluid. Chondroitin is the most abundant glycosaminoglycan found in cartilage. It constitutes proteoglycans which, together with collagen, grant resistance and elasticity to cartilage. Proteoglycans play an important role in creating hydrated spaces in the extracellular matrix. Glucosamine Sulphate (GS) and Chondroitin Sulphate (CS) are the most commonly used forms in research [14] [15].

The skin is the largest organ in the human body; it serves several functions and it covers the entire body surface area. It is constituted by the epidermis and dermis layers, receives one third of the blood flow, and its thickness varies throughout the body regions. The epidermis, outer layer of the skin, is subdivided into several other layers. Its outermost layer, the stratum corneum, serves the main function of the skin, which is to form a barrier to protect underlying tissue. The stratum corneum, along with its corneocytes and corneodesmosomes, forms a highly organized layer that is resistant to physical and chemical insults. In this respect, it is general knowledge that on account of that barrier it becomes difficult for medication to penetrate skin tissue [21].

The fact that skin absorption significantly decreases when the molecular weight of a substance is above $500 \mathrm{Da}$ and increases when the molecular weight is below $100 \mathrm{Da}$ must be observed. The partition coefficient of a substance between organic and aqueous phases is another important factor. Substances with low partition coefficients (below zero) display low lipophilicity, which will limit penetration through the stratum corneum. In substances which display partition coefficients between 1 and 4, skin absorption is increased [21] [22].

On the other hand, the advantages of transdermal treatment are widely debated on a broader scale, such treatment is said to be advantageous for its efficacy in treating localized situations, as it allows greater local concentration and it results in smaller systemic effects. Skin absorption is a three-stage process: penetration, permeation, and absorption. The latter occurs when a substance is absorbed into the bloodstream. This entire process may take place across four different pathways: the transcellular route (through stratum corneum cells); the intercellular route (within stratum corneum cells); the transfollicular/shunt route (through hair follicles); and the transglandular route (through sweat and sebaceous glands) [21] [22].

In this same context, it is important to observe that $\mathrm{OA}$ is very common in patients over 65 years of age. Oral drugs are frequently prescribed, posing cardiovascular, renal, and gastrointestinal risks for those individuals. Older patients normally use other orally administered drugs and may have difficulty in swallowing. In those cases, skin delivery provides better conditions for safety and tolerability [23].

Bioavailability is another key factor when comparing effects triggered by different drug administration routes. In that regard, it is important to observe the study conducted by Lee et al. [24]. They have created a system which allows for the encapsulation of Glucosamine Sulphate (GS) molecules at a salt concentra- 
tion of $10 \%$. The pharmacokinetic profiles of oral and topical dosage of GS were compared in mice. For human study, 15 healthy volunteers were given a single dose of $10 \mathrm{~g}$ of glucosamine cream, equivalent to $1000 \mathrm{mg}$ of GS on both of their knees. Concentration was measured through plasma analysis. The authors' findings strongly suggested that the high and sustainable level of GS in the blood, achieved through skin delivery, is able to provide means for cartilage regeneration. Said study showed the superiority of topical administration in the skin delivery of GS.

Strategies have been studied with the purpose to solve the problem with skin permeability. Among those strategies are the percutaneous absorption promoters, new pharmaceutical systems, and physical methods. That said, it can be observed that the recent inclination toward enhanced drug solubility and bioavailability for skin delivery is based upon nanostructured systems [25] [26] [27].

Research studies did not detail any form of skin preparation to receive the technique. There were only a few suggestions as to how the product was applied to the skin. It is also important to consider that absorption and permeation may vary according to individual skin differences, including level of hydration [28]. Hydration of the skin is one of the factors which can affect speed and degree of skin absorption. The more hydrated the skin is the more efficient drug absorption becomes through the skin [29]. Permeability and absorption degrees may be modified as the skin undergoes physical, chemical or biological changes which alter its characteristics [30].

The lack of standardization when preparing topical formulations as far as drug concentration is concerned was a critical point discussed in literature. There was great variation among studies and that hindered the conclusion process. There are many studies dedicated to assessing the minimal therapeutic dose for oral treatments [31] [32]. There are not enough studies which discuss the necessary dose for skin delivery.

The use of Glucosamine Hydrochloride, generally in the form of supplementation, is very common on trials via oral route [33] [34]. Combined use of orally administered GS and CS is often preferred as it shows better results when compared to single use [35] [36] [37]. However, there was no mention to these aspects in any of the 5 clinical trials reviewed. There are insufficient studies performed on combined and topically applied GS and CS pharmacokinetics.

\section{Conclusions}

Concerning skin delivery of GS and CS in treating OA of the knee, there is insufficient evidence as to: 1) most appropriate vehicle (aqueous, cream gel, or gel formulation?); 2) best daily dose (single or multiple applications?); 3) the importance of the skin state of hydration to permeability; 4) skin delivery associated with physical resources (iontophoresis, phonophoresis, occlusion, infrared) as enhancers; 5) different chemical agents as permeation enhancers; 6) most effective daily intake; and 7) the best type of treatment with these substances (if combined or used alone). 
With the purpose to enhance permeation and delivery of GS and CS to knee joint, combining the advantages of intravenous infusion therapy with the convenience of oral administration, the recommended course of action is to transform skin delivery technology of these substances. Within that same context, further clarification of the points raised in this review and the development of topical systems with nanotechnology may introduce a new perspective for future research.

\section{References}

[1] Bhatia, D., Bejarano, T. and Novo, M. (2013) Current Interventions in the Management of Knee Osteoarthritis. Journal of Pharmacy and Bioallied Sciences, 5, 30 38. https://doi.org/10.4103/0975-7406.106561

[2] Wilson, N., Sanchez-Riera, L., Morros, R., Diez-Perez, A., Javaid, M.K., Cooper, C., et al. (2015) Drug Utilization in Patients with Osteoosteo Arthritis: A PopulationBased Study. Rheumatology, 54, 860-867. https://doi.org/10.1093/rheumatology/keu403

[3] Batool, F., Sohail, M., Ashraf, F., Rana, B., Mahmood, F. and Tanveer, S. (2015) Clinical Effectiveness of Glucosamine and Chondroitin Sulphate in Treatment of Osteoarthritis. International Journal of Pharmaceutical Sciences and Research, 6, 541-545.

[4] Hochberg, M.C., Altman, R.D., April, K.T., Benkhalti, M., Benkhalti, M., Guyatt, G., et al. (2012) American College of Rheumatology 2012: Recommendations for the Use of Nonpharmacologic and Pharmacologic Therapies in Osteoarthritis of the Hand, Hip, and Knee. Arthritis Care \& Research, 64, 465-474. https://doi.org/10.1002/acr.21596

[5] Jevsevar, D.S., Brown, G.A., Jones, D.L., Matzkin, E.G., Manner, P.A., Mooar, P., et al. (2013) The American Academy of Orthopedic Surgeons Evidence-Based Guideline on Treatment of Osteoarthritis of the Knee. Journal of Bone and Joint Surgery, 21, 571-576.

[6] McAlindon, T.E., Bannuru, R.R., Sullivan, M.C., Arden, N.K., Berenbaum, F., Bierma-Zeinstra, S.M., et al. (2014) Osteoarthritis Research Society International Guidelines for the Non-Surgical Management of Knee Osteoarthritis. Osteoarthritis Cartilage, 22, 363-388.

[7] Silva, J.A., Apolinário, A.C., Souza, M.S.R., Damasceno, B.P.G.L. and Medeiros, A.C.D. (2010) Cutaneous Administration of Drugs: Challenges and Strategies for the Development of Trans-dermal Formulations. Revista de Ciências Farmacêuticas Básica, 31, 125-131.

[8] Jalón, E.G., Josa, M., Campanero, M.A., Santoyo, S. and Ygartua, P. (2000) Determination by High-Performance Liquid Chromatography of Ketoprofen in Vitro in Rat Skin Permeation Samples. Journal of Chromatography A, 870, 143-149.

[9] Bortolon, F.F., Sato, M.E., Andreazza, R.C.S. and Bresolin, T.M.B. (2008) Effect of Enhancers on the in Vitro Percutaneous Absorption of Piroxicam from Compounding Formulations. Revista Brasileira de Farmácia, 44, 433-449.

[10] Badran, M.M., Kuntsche, J. and Fahr, A. (2009) Skin Penetration Enhancement by a Microneedle Device in Vitro: Dependency on Needle Size and Applied Formulation. European Journal of Pharmaceutical Sciences, 36, 511-523. https://doi.org/10.1016/j.ejps.2008.12.008

[11] Chorilli, M., Brizante, A.C., Rodrigues, C.A. and Salgado, H.R.N. (2007) General 
Aspects in Transdermal Systems of Drugs Release. Revista Brasileira de Farmácia, 88, 7-13.

[12] Gill, H.S., Andrews, S.N., Sakthivel, S.K., Fedanov, A., William, I.R., Garber, D.A., et al. (2009) Selective Removal of Stratum Corneum by Microdermabrasion to Increase Skin Permeability. European Journal of Pharmaceutical Sciences, 38, 95-103. https://doi.org/10.1016/j.ejps.2009.06.004

[13] Bruyère, O., Cooper, C., Pelletier, J.P., Branco, J., Brandi, L.M., Guillemin, F., et al. (2014) An Algorithm Recommendation for the Management of Knee Osteoarthritis in Europe and Internationally: A Report from a Task Force of the European Society for Clinical and Economic Aspects of Osteoporosis and Osteoarthritis (ESCEO). Seminars in Arthritis and Rheumatism, 44, 253-263.

[14] Hauselmann, H.J. (2001) Nutripharmaceuticals for Osteoarthritis. Best Practice and Research Clinical Rheumatology, 15, 595-607.

https://doi.org/10.1053/berh.2001.0176

[15] Velosa, A.P.P., Teodoro, W.R. and Yoshinari, N.H. (2003) Collagen in Osteoarthrotic Cartilage. Revista Brasileira de Reumatologia, 43,160-166. https://doi.org/10.1590/S0482-50042003000300006

[16] Cohen, M., Wolfe, R., Mai, T. and Lewis, D. (2003) A Randomized, Double Blind, Placebo Controlled Trial of a Topical Cream Containing Glucosamine Sulfate, Chondroitin Sulfate, and Camphor for Osteoarthritis of the Knee. The Journal of Rheumatology, 30, 523-528.

[17] Erhan, B., Gunduz, B., Üstunel, S.H., Bardak, A.N., Feride, S., Gülsün, I. and Zuhal, K. (2012) The Efficacy of Topical Glucosamine Sulfate-Chondroitin Sulfate in Knee Osteoarthritis Treated With Physical Therapy: A Randomized, Double-Blind, Placebo-Controlled Study. Turkish Journal of Physical Medicine and Rehabilitation, 58, 194-198.

[18] Hammad, Y.H., Hala, R.M. and Sobhy, M.M. (2015) Clinical and Biochemical Study of the Comparative Efficacy of Topical versus Oral Glucosamine/Chondroitin Sulfate on Osteoarthritis of the Knee. The Egyptian Rheumatologist, 37, 85-91. https://doi.org/10.1016/j.ejr.2014.06.007

[19] Onigbinde, A.T., Talabi, A.E., Okulaja, I.A. and Dominic, O. (2011) Comparative Efficacy of Cycle-Ergometry Exercise and Glucosamine Sulphate Iontophoresis in Pain Management of Subjects with Sub-Acute Knee Osteoarthritis. Medicina Sportiva, 3, 1517-1521.

[20] Onigbinde, A.T., Adesina, O.D., Tarimo, N. and Ojoawo, A. (2014) Comparative Effects of a Single Treatment Session Using Glucosamine Sulphate and Methyl Salicylate on Pain and Hamstring Flexibility of Patients with Knee Osteoarthritis. American Journal of Health Research, 2, 40-44.

[21] Kielhorn, J., Melching-Kollmu, S. and Mangelsdorf, I. (2006) Environmental Health Criteria (EHC) 235: Dermal Absorption. World Health Organization, 102, 6-36.

[22] Pellanda, C., Ottiker, E., Strub, C., Figueiredo, V., Rufli, T., Imanidis, G. and Surber, C. (2006) Topical Bioavailability of Triamcinolone Acetonide: Effect of Dose and Application Frequency. Archives of Dermatological, 298, 221-230. https://doi.org/10.1007/s00403-006-0677-x

[23] Argoff, C.E. and Gloth, F.M. (2011) Topical Nonsteroidal Anti-Inflammatory Drugs for Management of Osteoarthritis in Long-Term Care Patients. Therapeutics and Clinical Risk Management, 7, 393-399.

[24] Lee, C.W., et al. (2005) The Transdermal Profiles of Mediflex. Glucosamine Cream in Mouse and Man. National Congress of Indonesian Society of Rheumatology. 
[25] Zhao, Y., Moddaresi, M., Jones, S.A. and Brown, M.B. (2009) A Dynamic Topical Hydrofluoroal Kanefoam to Induce Nanoparticle Modification and Drug Release in Situ. European Journal of Pharmaceutics and Biopharmaceutics, 72, 521-528. https://doi.org/10.1016/j.ejpb.2009.03.002

[26] Morey, T.E., Modell, J.H., Shekhawat, D., Shah, D.O., Klatt, B., Thomas, G.P., et al. (2006) Anesthetic Properties of a Propofol Microemulsion in Dogs. Anesthesia \& Analgesia, 103, 882-887. https://doi.org/10.1213/01.ane.0000237126.57445.80

[27] Silva, J.A., Bedor, D.G.C., Damasceno, B.P.G.L., Oliveira, A.G., Egito, E.S.T. and Santana, D.P. (2009) Physicochemical Characterization and Development of a Microemulsion System for Transdermal Use. Journal of Dispersion Science and Technology, 31, 1-8.

[28] Sioufi, A., Pommier, F., Boschet, F., Godbillon, J., Lavoignat, D. and Salliere, D. (1994) Percutaneous Absorption of Diclofenac in Healthy Volunteers after Single and Repeated Skin Delivery of Diclofenac Emulgel. Biopharmaceutics \& Drug Disposition, 15, 441-449.

[29] Thomas, B.J. and Finnin, B.C. (2004) The Transdermal Revolution. Drug Discovery Today, 9, 697-703. https://doi.org/10.1016/S1359-6446(04)03180-0

[30] Kaestli, L.Z, Wasilewski-Rasca, A.F., Bonnabry P. and Vogt-Ferrier, N. (2008) Use of Transdermal Drug Formulations in the Elderly. Drugs Aging, 25, 269-280. https://doi.org/10.2165/00002512-200825040-00001

[31] Persiani, S., Roda, E., Rovati, L.C., Locatelli, M., Giacovelli, G. and Roda, A. (2005) Oral Bioavailability and Plasma Pharmacokinetics after Increasing Doses of Crystalline Glucosamine Sulfate in Man. Osteoarthritis Cartilage, 13, 1041-1049. https://doi.org/10.1016/j.joca.2005.07.009

[32] Persiani, S., Rotin, R., Trisolino, G., Rovati, L.C., Locatelli, M., Paganini, D., et al. (2007) Synovial and Plasma Glucosamine Concentrations in Osteoarthritic Patients Following Oral Crystalline Glucosamine Sulphate at Therapeutic Dose. Osteoarthritis Cartilage, 15, 764-772. https://doi.org/10.1016/j.joca.2007.01.019

[33] Kwoh, C.K., Roemer, F.W., Hannon, M.J., Moore, C.E., Jakicic, J.M., Guermazi, A., et al. (2014) Effect of Oral Glucosamine on Joint Structure in Individuals with Chronic Knee Pain. Arthritis \& Rheumatology, 66, 930-939. https://doi.org/10.1002/art.38314

[34] Messier, S.P., Mihalko, S., Loeser, R.F., Legault, C., Jolla, J., Pfruender, J., et al. (2007) Glucosamine/Chondroitin Combined with Exercise for the Treatment of Knee Osteoarthritis: A Preliminary Study. Osteoarthritis Cartilage, 15, 1256-1266. https://doi.org/10.1016/j.joca.2007.04.016

[35] Irsay, L., Borda, M.I., Nitu, A.D., Ciortea, V., Onac, I. and Ungur, R. (2010) Effectiveness of Glucosamine and Chondroitin Sulfate Combination in Patients with Primary Osteoarthritis. Applied Medical Informatics, 27, 47-54.

[36] Clegg, D.O., Reda, D.J., Harris, C.L., Klein, M.A., O’Dell, J.R., Hooper, M.M., et al. (2006) Glucosamine, Chondroitin Sulfate, and the Two in Combination for Painful Knee Osteoarthritis. The New England Journal of Medicine, 354, 795-808. https://doi.org/10.1056/NEJMoa052771

[37] Henrotin, Y. and Lambert, C. (2013) Chondroitin and Glucosamine in the Management of Osteoarthritis. Current Rheumatology Reports, 15, 1-9. 
Submit or recommend next manuscript to SCIRP and we will provide best service for you:

Accepting pre-submission inquiries through Email, Facebook, LinkedIn, Twitter, etc. A wide selection of journals (inclusive of 9 subjects, more than 200 journals)

Providing 24-hour high-quality service

User-friendly online submission system

Fair and swift peer-review system

Efficient typesetting and proofreading procedure

Display of the result of downloads and visits, as well as the number of cited articles Maximum dissemination of your research work

Submit your manuscript at: http://papersubmission.scirp.org/

Or contact jbm@scirp.org 